NASA/TM-2004-213098

\title{
Atomic Oxygen Durability Evaluation of a UV Curable Ceramer Protective Coating
}

Bruce A. Banks

Glenn Research Center, Cleveland, Ohio

Christina A. Karniotis

QSS Group, Inc., Cleveland, Ohio

David Dworak and Mark Soucek

University of Akron, Akron, Ohio 
Since its founding, NASA has been dedicated to the advancement of aeronautics and space science. The NASA Scientific and Technical Information (STI) Program Office plays a key part in helping NASA maintain this important role.

The NASA STI Program Office is operated by Langley Research Center, the Lead Center for NASA's scientific and technical information. The NASA STI Program Office provides access to the NASA STI Database, the largest collection of aeronautical and space science STI in the world. The Program Office is also NASA's institutional mechanism for disseminating the results of its research and development activities. These results are published by NASA in the NASA STI Report Series, which includes the following report types:

- $\quad$ TECHNICAL PUBLICATION. Reports of completed research or a major significant phase of research that present the results of NASA programs and include extensive data or theoretical analysis. Includes compilations of significant scientific and technical data and information deemed to be of continuing reference value. NASA's counterpart of peerreviewed formal professional papers but has less stringent limitations on manuscript length and extent of graphic presentations.

- TECHNICAL MEMORANDUM. Scientific and technical findings that are preliminary or of specialized interest, e.g., quick release reports, working papers, and bibliographies that contain minimal annotation. Does not contain extensive analysis.

- CONTRACTOR REPORT. Scientific and technical findings by NASA-sponsored contractors and grantees.
- CONFERENCE PUBLICATION. Collected papers from scientific and technical conferences, symposia, seminars, or other meetings sponsored or cosponsored by NASA.

- SPECIAL PUBLICATION. Scientific, technical, or historical information from NASA programs, projects, and missions, often concerned with subjects having substantial public interest.

- TECHNICAL TRANSLATION. Englishlanguage translations of foreign scientific and technical material pertinent to NASA's mission.

Specialized services that complement the STI Program Office's diverse offerings include creating custom thesauri, building customized databases, organizing and publishing research results ... even providing videos.

For more information about the NASA STI Program Office, see the following:

- Access the NASA STI Program Home Page at http://www.sti.nasa.gov

- E-mail your question via the Internet to help@sti.nasa.gov

- Fax your question to the NASA Access Help Desk at 301-621-0134

- Telephone the NASA Access Help Desk at 301-621-0390

- Write to:

NASA Access Help Desk

NASA Center for AeroSpace Information 7121 Standard Drive

Hanover, MD 21076 
NASA/TM-2004-213098

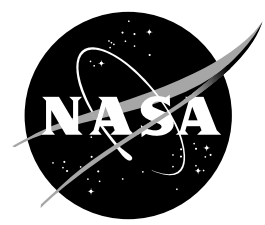

\section{Atomic Oxygen Durability Evaluation of a UV Curable Ceramer Protective Coating}

Bruce A. Banks

Glenn Research Center, Cleveland, Ohio

Christina A. Karniotis

QSS Group, Inc., Cleveland, Ohio

David Dworak and Mark Soucek

University of Akron, Akron, Ohio

Prepared for the

Seventh International Conference on Protection of Materials and Structures from Space Environment cosponsored by Materials and Manufacturing Ontario and The Centre for Research in Earth and Space Technology (CRESTech)

Toronto, Canada, May 10-13, 2004

National Aeronautics and

Space Administration

Glenn Research Center 


\section{Acknowledgments}

The authors gratefully acknowledge Justin Tokash and Dr. Rex Ramsier, University of Akron, Physics Department, for their XPS contributions.

Available from

NASA Center for Aerospace Information 7121 Standard Drive

Hanover, MD 21076
National Technical Information Service 5285 Port Royal Road Springfield, VA 22100

Available electronically at http:/ /gltrs.grc.nasa.gov 


\title{
Atomic Oxygen Durability Evaluation of a UV Curable Ceramer Protective Coating
}

\author{
Bruce A. Banks \\ National Aeronautics and Space Administration \\ Glenn Research Center \\ Cleveland, Ohio 44135 \\ Christina A. Karniotis \\ QSS Group, Inc. \\ Cleveland, Ohio 44135 \\ David Dworak and Mark Soucek \\ University of Akron \\ Akron, Ohio 44325
}

\begin{abstract}
The exposure of most silicones to atomic oxygen in low Earth orbit (LEO) results in the oxidative loss of methyl groups with a gradual conversion to oxides of silicon. Typically there is surface shrinkage of oxidized silicone protective coatings which leads to cracking of the partially oxidized brittle surface. Such cracks widen and branch crack with continued atomic oxygen exposure ultimately allowing atomic oxygen to reach any hydrocarbon polymers under the silicone coating. A need exists for a paintable silicone coating that is free from such surface cracking and can be effectively used for protection of polymers and composites in LEO. A new type of silicone based protective coating holding such potential was evaluated for atomic oxygen durability in an RF atomic oxygen plasma exposure facility. The coating consisted of a UV curable inorganic/organic hybrid coating, known as a ceramer, which was fabricated using a methyl substituted polysiloxane binder and nanophase silicon-oxo-clusters derived from sol-gel precursors. The polysiloxane was functionalized with a cycloaliphatic epoxide in order to be cured at ambient temperature via a cationic UV induced curing mechanism. Alkoxy silane groups were also grafted onto the polysiloxane chain, through hydrosilation, in order to form a network with the incorporated silicon-oxo-clusters. The prepared polymer was characterized by ${ }^{1} \mathrm{H}$ and ${ }^{29} \mathrm{Si}$ NMR, FT-IR, and electrospray ionization mass spectroscopy. The paper will present the results of atomic oxygen protection ability of thin ceramer coatings on Kapton $\mathrm{H}$ as evaluated over a range of atomic oxygen fluence levels.
\end{abstract}

Key words: Atomic oxygen, silicones

\subsection{INTRODUCTION}

Silicones are one of the few polymers that can be applied by painting or spraying over composite or other organic spacecraft materials which have afforded reasonable protection from low Earth orbital (LEO) atomic oxygen attack. The gradual oxidation of the silicones in LEO results in an oxidized silicone surface which becomes a silicate or silica (Refs. 1-3). This surface conversion from silicone to silica also tends to produce tensile stresses in the surface of the oxidized silicone with an increase in the surface microhardness as a result of atomic oxygen reaction with the silicone (Ref. 4). A variety 
of approaches have been or are now being explored to identify silicones, silicone copolymers or silicone-hydrocarbon blends that provide flexibility as well as atomic oxygen protection (Refs. 5-8). Results to date indicate that hybrid polymers composed of inorganic and organic polymers hold potential to survive LEO atomic oxygen attack. The silicones which are dominated by a oxygen-to-silicon ratio of 1.5 have shown greater resistance to atomic oxygen attack than the silicones with a ratio of 1.0. Polyhedral oligomeric silsesquioxane (POSS) contains covalently bonded reactive functionalities appropriate for polymerization or grafting. It can be blended or copolymerized with many aerospace polymers and is being considered for atomic oxygen durability (Ref. 8). The resistance to atomic oxygen attack of silicone blended or copolymerized polymers has been dependent not only on the oxygen-to-silicone ratio but the fractional fill of the silicone. The challenge to make functional use of such blends has been to find an adequately silicone-filled polymer which contains the appropriate protective silicone such that it has acceptable atomic oxygen durability, volatility, optical, thermal, mechanical and ease of application properties.

Because of their ability to provide atomic oxygen protection, thermal stability, flexibility, and stability; polysiloxanes are an attractive candidate solution to achieving ideal protection from the elements of space. However, this is just part of the solution. The vacuum ultraviolet (VUV) radiation and high energy particles can still damage and degrade the composite material. Therefore, to incorporate protection from those components as well, ceramer coatings; which are inorganic/organic hybrid materials, can be utilized. Ceramers are part ceramic (inorganic) and part polymer (organic) and can offer protection from atomic oxygen as well as UV radiation and high energy particles via the in situ fabrication of nanophase silicon-oxo-clusters (Refs. 9 and 10). The siliconoxo-clusters are formed through a series of hydrolysis and condensation reactions between sol-gel precursors.

The intention of a ceramer approach is to acquire a synergistic effect between the inorganic and organic phases on a nanoscale through the use of phase coupling agents, which for this system are alkoxy silanes pendant from the polysiloxane chain. There is confirmation of a synergy between the phases and this approach affords a uniformly distributed nanophase within a continuous organic phase (Ref.11). Once the coating is exposed to atomic oxygen, a protective layer of silicon oxide is formed and, with the incorporation of silicon-oxo-clusters, the coating should protect the composite material against atomic oxygen erosion, high energy particles, and VUV radiation. Figure 1 is an overall diagram of the coating's function (Ref.12). 


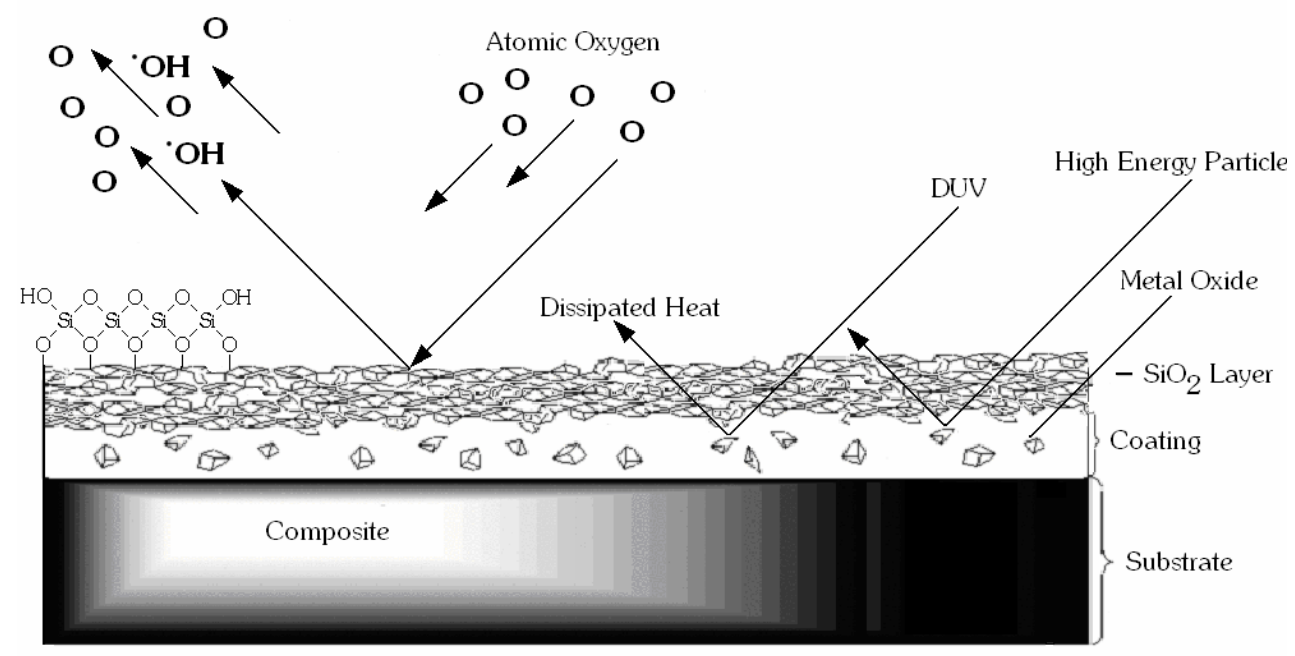

Figure 1. - Depiction of the formation and function of protective silicon oxide layer and silicon-oxo-clusters.

This paper summarizes an investigation of the high fluence atomic oxygen durability of ultraviolet radiation curable ceramer protective coating consisting of methyl substituted polysiloxane and compares the results with the commonly used silicone coating DC93500 .

\subsection{MATERIALS: METHYL SUBSTITUTED POLYSILOXANE}

\subsection{Synthesis}

\section{Experimental}

\section{Materials}

Octamethylcyclotetrasiloxane, 1,3,5,7-tetramethylcyclotetrasiloxane, 1,1,3,3 tetramethyldisiloxane, and vinyl triethoxysilane were purchased from Gelest, Inc. and used as supplied. Wilkinson's catalyst (chlorotris (triphenylphosphine) rhodium(I), 99.99\%), Amberlyst 15 ion-exchange resin, and 4-vinyl-1-cyclohexene 1,2-epoxide were purchased from Aldrich and used as supplied. Toluene, supplied by Aldrich Chemical Co., was distilled in order to eliminate any impurities. Irgacure 250 was supplied by Ciba Specialty Chemicals and used as received. Air sensitive materials were transferred and weighed in an inert atmosphere dry box under argon. 

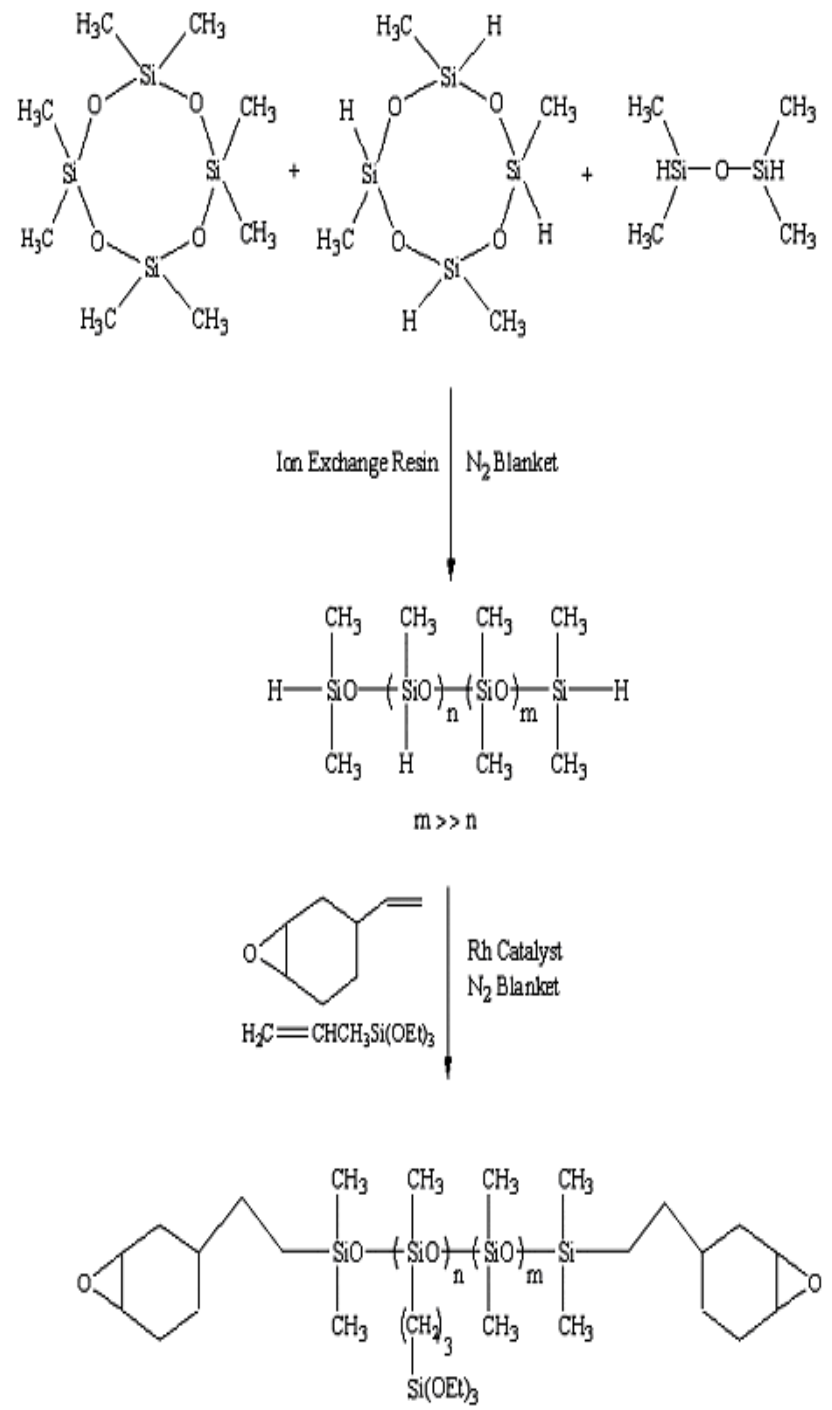

Figure 2. - Synthesis of poly (dimethylsiloxane-co-methylhydrosiloxane), hydride terminated.

\section{Synthesis of poly(dimethylsiloxane-co-methylhydrosiloxane), hydride terminated}

To a three neck round bottom flask equipped with a reflux condenser and nitrogen inlet/outlet was added octamethylcyclotetrasiloxane $(90.00 \mathrm{~g}), 1,3,5,7$ tetramethylcyclotetrasiloxane (5.33 g), 1,1,3,3-tetramethyldisiloxane (0.67 g), and Amberlyst $15(20 \mathrm{wt} \%)$ and stirred at $90{ }^{\circ} \mathrm{C}$, under nitrogen, for $15 \mathrm{~h}$. The viscous solution was then filtered to obtain poly(dimethylsiloxane-co-methylhydrosiloxane), hydride terminated of various molecular weight ranges. Vacuum filtration was performed $(<1 \mathrm{~mm} \mathrm{Hg})$ in order to remove low molecular weight oligomers and unreacted starting materials. Weight average molecular weight was obtained from gel permeation 
chromatography (GPC) analysis, $\mathrm{M}_{\mathrm{w}}=42,000, \mathrm{PDI}=1.66$. Polymer characterization and $\mathrm{Si}-\mathrm{H}$ functionality was confirmed/analyzed through ${ }^{1} \mathrm{H}$ NMR, FT-IR, and titration. ${ }^{1} \mathrm{HNMR}\left((\mathrm{ppm}), \mathrm{CDCl}_{3}\right): 4.675$ (s, $\left.\mathrm{CH}_{3}-\mathrm{Si}-\mathrm{H}\right)$. FT-IR (cm ${ }^{-1-}, \mathrm{KBr}$ Plate): 2150 (s, Si-H.

\section{Cycloaliphatic epoxide and alkoxy silane functionalization of prepared poly(dimethylsiloxane-co-methylhydrosiloxane), hydride terminated.}

To a three neck round bottom flask, equipped with a reflux condenser and nitrogen inlet/outlet was added was added poly(dimethylsiloxane-co-methylhydrosiloxane), hydride terminated (30 g), 4-vinyl-1-cyclohexene diepoxide (20 g), vinyl triethoxysilane (2 g), and Wilkinson's catalyst $(0.004 \mathrm{~g})$. Via a canula, distilled toluene $(30 \mathrm{~g})$ was added. The reaction was held at $75^{\circ} \mathrm{C}$ by means of an oil bath and mechanically stirred under a nitrogen blanket. The disappearance of the Si-H functionality was monitored through FTIR and the disappearance of the peak at $\sim 2160 \mathrm{~cm}^{-1}$ indicated that the reaction was complete. Any solvent and unreacted starting materials were removed under vacuum $(3-5 \mathrm{~mm} \mathrm{Hg})$. Cycloaliphatic epoxide and alkoxy silane functionalization was confirmed/analyzed through ${ }^{1} \mathrm{H}$ NMR, FT-IR analysis, and titration.

\subsection{Structure}

Once cured the coating should form a strong interlocking network consisting of a cross linked polysiloxane phase with interconnected silicon-oxo-clusters (Figure 3). The silicon-oxo-clusters will be connected to the polysiloxane backbone though hydrolysis and condensation reactions with the tethered alkoxy silane.

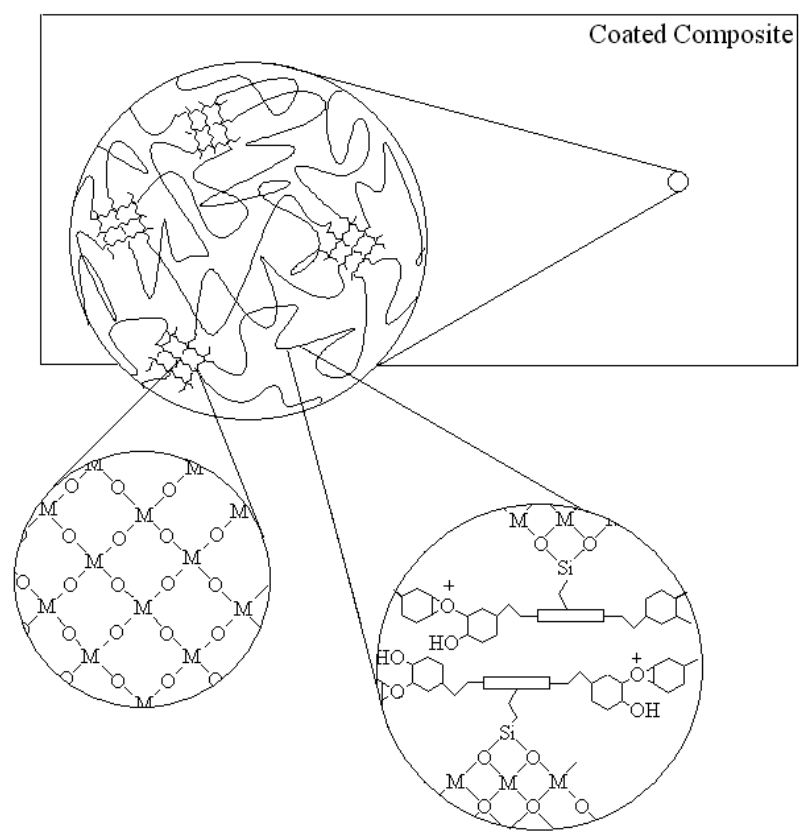

Figure 3. - Structure of cross linked polysiloxane phase with interconnected silicon-oxoclusters. 


\subsection{APPARATUS AND PROCEDURE}

\subsection{Coating Application}

The polysiloxane was diluted with dry toluene $(25 \% \mathrm{w} / \mathrm{w})$ in order to reduce the viscosity. Sol-gel precursor $(5 \% \mathrm{w} / \mathrm{w})$ and photo initiator $(3 \% \mathrm{w} / \mathrm{w})$ was also added to the solution and thoroughly mixed. A piece of Kapton $\mathrm{H}(\sim 4$ inches in diameter) was mounted onto a spinning stage and spun at a very high speed. The polysiloxane solution was dropped onto the center of the spinning Kapton sample. The sample was removed from the stage and passed through a UV curing chamber with a belt speed of $25 \mathrm{ft} / \mathrm{min}$ and an average intensity of $150 \mathrm{~mW} / \mathrm{cm}^{2}$. The coating thickness was measured with a coating thickness gauge and AFM. Both methods confirmed an average of a two micrometer thickness.

\section{Instruments}

Viscosity measurements were taken on an AR 500 Rheometer (Thermal Analysis) equipped with a cup and bob sample holder and operated at $21.1^{\circ} \mathrm{C}$. Pencil harness tests were conducted according to ASTM method D3363-00. Taber scratch test was performed using a Taber Shear/Scratch Tester model 502 and conforming to ASTM method G171-03. Taber Abrasion tests were conducted on a Taber Industries 5130 Abraser using a CS-10 test wheel. Taber abrasion studies corresponded to ASTM method D552-93a.

Thermogravimetric analysis was performed on a TGA Q 500 (Thermal Analysis).

X-ray photoelectron spectroscopy was completed on a Kratos Model ES3000 with a nonmonochromatic 120 Watt Al K-Alpha radiation source under $10^{-8}$ torr. Scanning electron microscopy was performed on a Hitachi S-2150 operating at $15 \mathrm{kV}$. Atomic force microscopy was performed on a multimode scanning probe microscope (Digital Instruments) using the tapping mode.

\subsection{Atomic Oxygen Exposure}

Samples of the ceramer silicone-coated Kapton H polyimide (with silicone coat on both sides) were compared with samples of DC 93-500 silicone-coated Kapton H (with silicone coat on one side) for atomic oxygen durability. The same coatings were also applied to fused silica substrates for the purposes of obtaining changes in optical properties as well as noting evidence of tensile cracking. Optical properties changes (reflectance, transmittance and absorptance) and mass loss were documented at atomic oxygen effective fluence levels of $2.22 \times 10^{21}$ and $1.38 \times 10^{22}$ atoms $/ \mathrm{cm}^{2}$. Kapton $\mathrm{H}$ witness samples were used to determine the effective atomic oxygen fluence as described in ASTM E 2089-00, "Standard Practices for Ground Laboratory Atomic Oxygen Interaction Evaluation of Materials for Space Applications". (Ref. 13) All Kapton H substrates used for coating evaluation and fluence witnesses were made of $2.54 \mathrm{~cm}$ diameter by $0.127 \mathrm{~mm}$ thick Kapton $\mathrm{H}$ polyimide. An additional set of ceramer and DC93-500 silicone coated samples were made that were scratched prior to exposing to atomic oxygen using finger wiping with laboratory dust. This was done to see if minor 
abrasion of the silicone surface would cause preferential cracking of the silicone coatings with atomic oxygen exposure. Samples of silicone-coated Kapton H were punched out and vacuum dehydrated for 48 hours prior to weighing to minimize mass uncertainty due to weight loss as recommended by ASTM E 2089-00. (Ref. 13). Atomic oxygen testing was performed on samples that were placed in an SPI Plasma Prep II 13.56 MHz radio frequency plasma asher. The ashers are typically operated on air at a pressure of 12.7 to $16 \mathrm{~Pa}$ (95-120 mTorr). The samples were each held down by fine wires attached to a metal frame (as shown in Figure 4) laying on a glass plate to minimize curling of the samples with atomic oxygen exposure from only one side.

Curling typically occurs for silicone coated samples that are coated on one side and could allow atomic oxygen to attack the uncoated back of the samples which would compromise the sample weight loss data. The plasma asher was operated at a Kapton effective flux of $4.69 \times 10^{15}$ atoms $/\left(\mathrm{cm}^{2} \mathrm{sec}\right)$ (Ref. 13).

Because many silicones used on LEO spacecraft have a history of causing contamination on spacecraft as a result of evolution of volatile silicones and with subsequent oxidation and conversion to silica on neighboring spacecraft surfaces, cross contamination witness samples were placed in the plasma ashers next to the silicone coated samples to assess the degree of silicone transport and resulting contamination. Tests were performed prior to sample exposures to validate that any contamination deposited would be as a result of the samples contained within the plasma asher. Thicknesses of deposited contaminants were measured using a Dektak 6M stylus profilometer which scanned the contamination coated

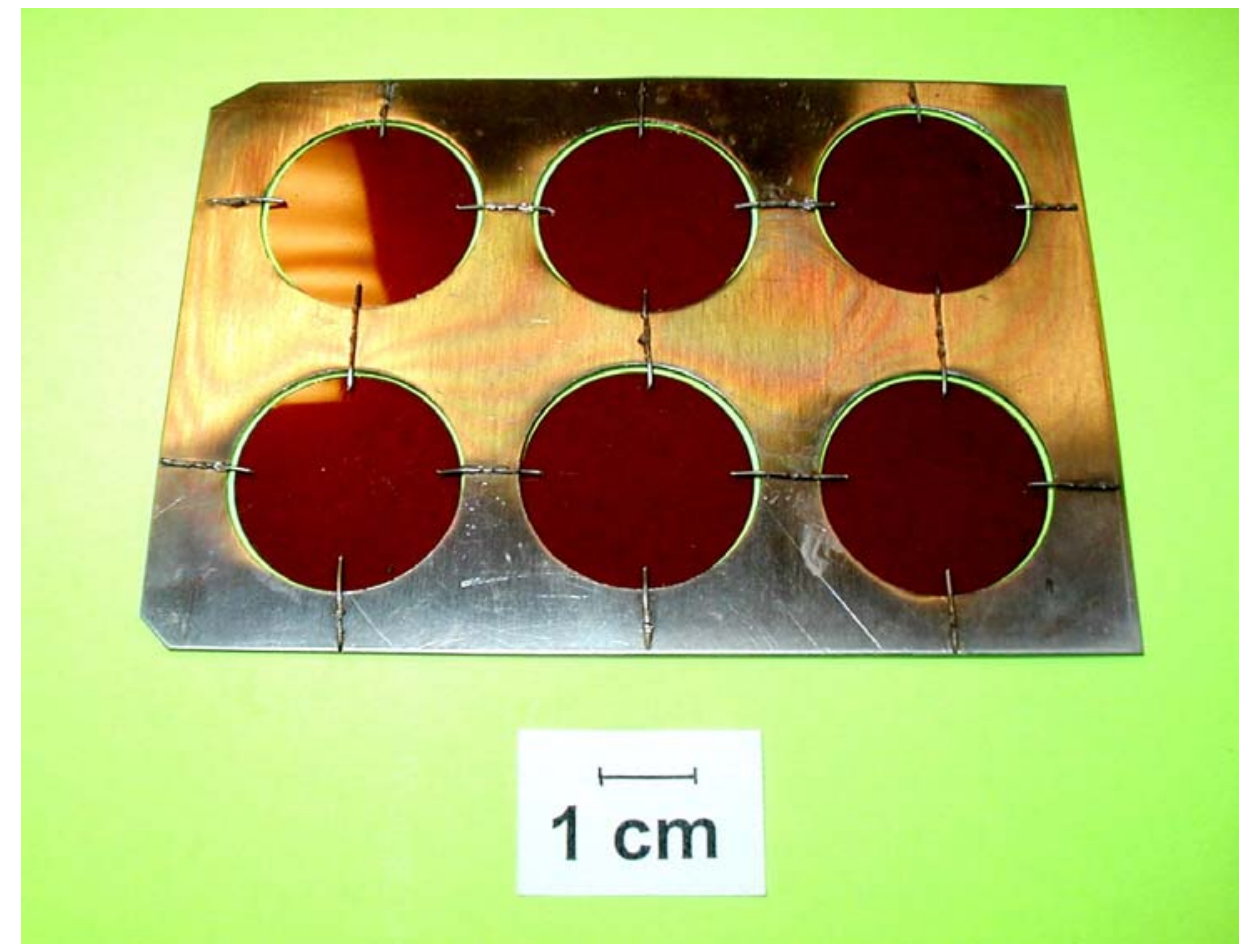

Figure 4. - Sample holder to prevent curling of $2.54 \mathrm{~cm}$ diameter samples when they were exposed to atomic oxygen. 
fused silica slide from the deposited area to an area that was protected from contamination deposition by means of a tightly fitted aluminum foil mask. Optical properties changes from prior to and after atomic oxygen exposure were made using a Perkin Elmer Lambda-19 spectrophotometer.

\subsection{RESULTS AND DISCUSSION}

\subsection{Methyl Substituted Polysiloxane Characterization}

The abrasion and scratch resistance of the cured coating were studied to determine how susceptible it is to physical damage. The Taber abrasion and scratch tests yielded a value of 183 wear cycles per mil and a scratch value of 50 grams. Both of these values are low and show that the coating has poor abrasion resistance. These values were checked using the pencil hardness test, which gave a value of $2 \mathrm{~B} / \mathrm{B}$. This value is also low and this trend could be a result of the very low glass transition temperature of the coating, which is approximately $-130{ }^{\circ} \mathrm{C}$. Such a low glass transition temperature makes the coating soft and vulnerable to damage. Varying the pendant group to raise the glass transition of the coating could be a potential answer in improving the abrasion resistance.

Thermal gravimetric analysis was performed in order to observe the thermal stability of the crosslinked polysiloxanes. Irreversible changes to the crosslinked structure of silicone polymers unavoidably occur at high temperatures due to chain scission or oxidative cross-linking (Ref. 14). In an inert atmosphere, depolymerization occurs with the loss of volatile products, mostly low molecular weight cyclic oligomers; but is often catalyzed by traces of acids, bases, water, or residual catalyst used in the polymers original production (Ref. 15). Typically, depolymerization occurs near $400{ }^{\circ} \mathrm{C}$ for reasonably pure polydimethylsiloxane (Ref. 16).

Thermal gravimetric analysis of the cured coatings illustrates the loss of small molecular weight oligomers in the early stages of the analysis (Figure 5). As expected, the depolymerization occurs near $400{ }^{\circ} \mathrm{C}$ for the sample tested. The range of molecular weights give way to the multiple slopes the curve exhibits. It is also important to note that the sample generated a small amount of residue $(\sim 13 \%)$, which can be attributed to the silicon-oxo-clusters formed during the polymerization process and high molecular weight chains that may not have completely volatized/degraded.

One of the most important aspects of the coating is the presence of the silicon-oxo-clusters. By utilizing the AFM's tapping mode, it will be possible to detect "hard" (silicon-oxoclusters) and "soft" (polymer) regions within the crosslinked polymer network. These clusters provide additional protection against high-energy particles and deep UV light. Figure 6 is an AFM image of a sample with 5\% (w/w) sol-gel precursor added prior to casting. The silicon-oxo-clusters are clearly visible in the subjected sample. The average size for the methyl substituted polysiloxane nano phase is $125 \mathrm{~nm}$. Figure 6 shows a more disperse and uniformly sized nanophase, which could be attributed to the small size of the pendant methyl group allowing more freedom to the growing nano clusters. 


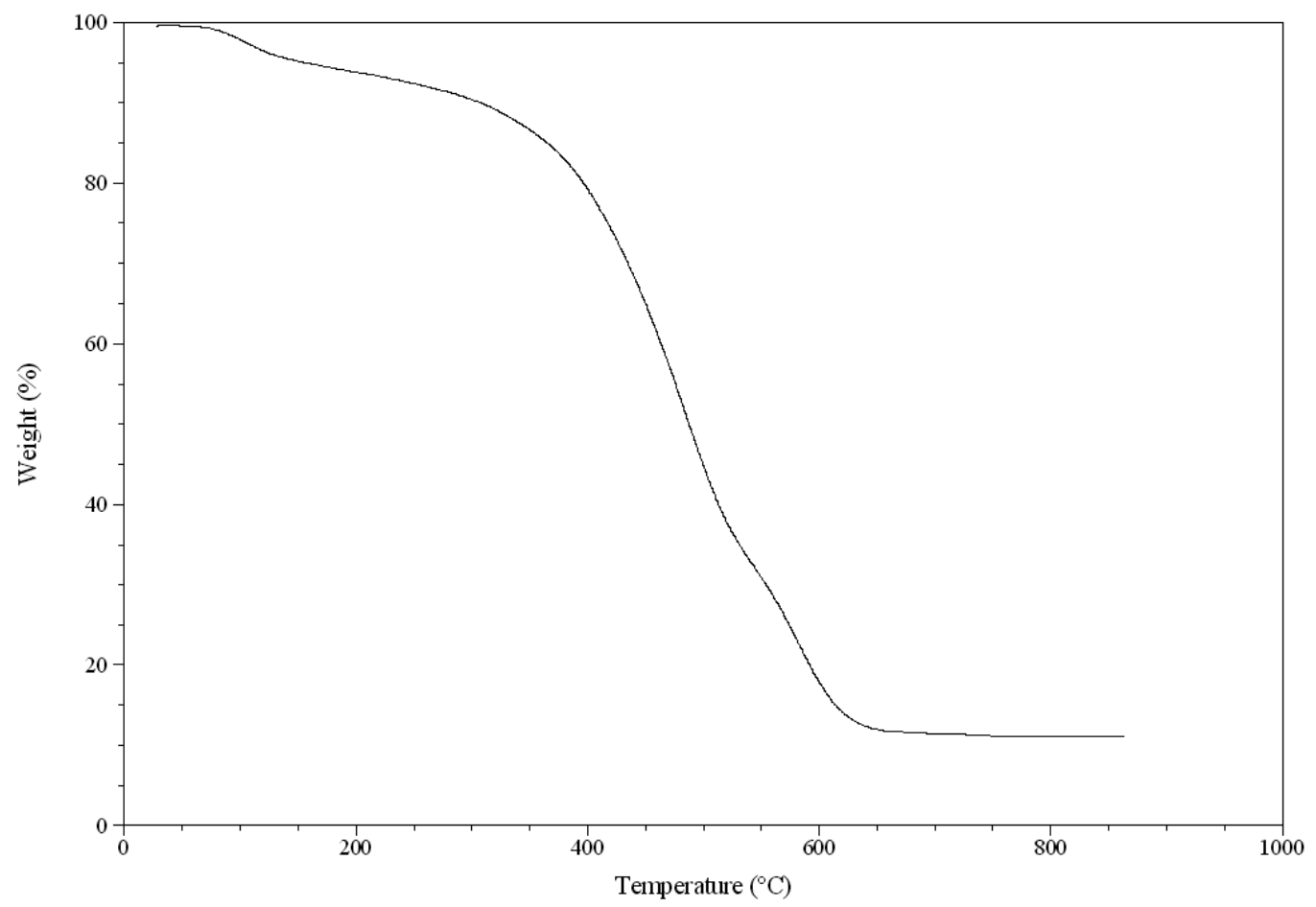

Figure 5. - Thermal Gravimetric Analysis of Cured Coating with 5\% Sol-gel precursor

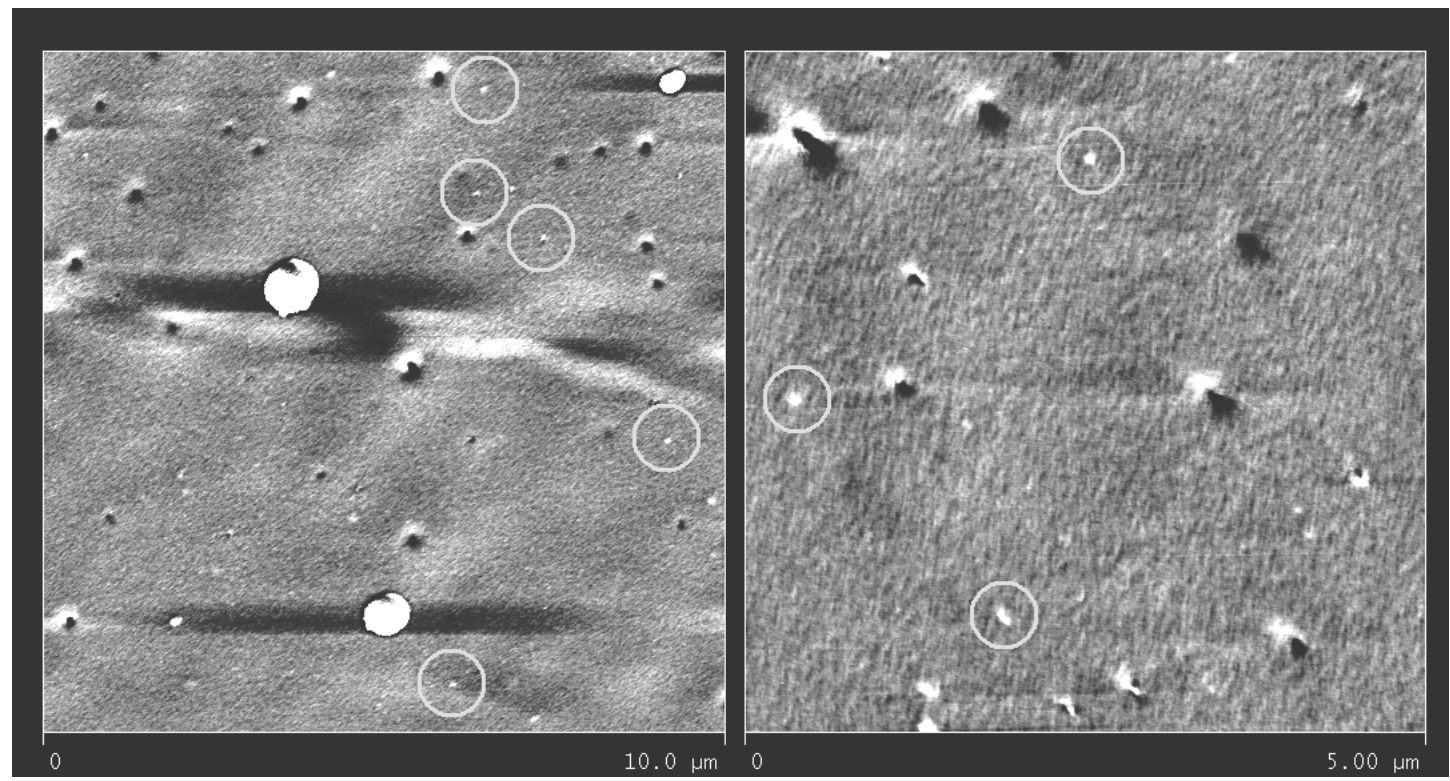

Figure 6. - AFM images of crosslinked methyl polysiloxane substituted with 5\% sol-gel precursor. 
Conductivity tests were performed on the crosslinked coatings. The coatings showed no signs of electrical conductivity, which is expected due to their insulating nature (Ref. 14).

\subsection{Atomic Oxygen Exposure Results}

Photographs of the silicone coated Kapton $\mathrm{H}$ samples and silicone coated fused silica samples after two different levels of atomic oxygen exposure are shown in Figure 7.

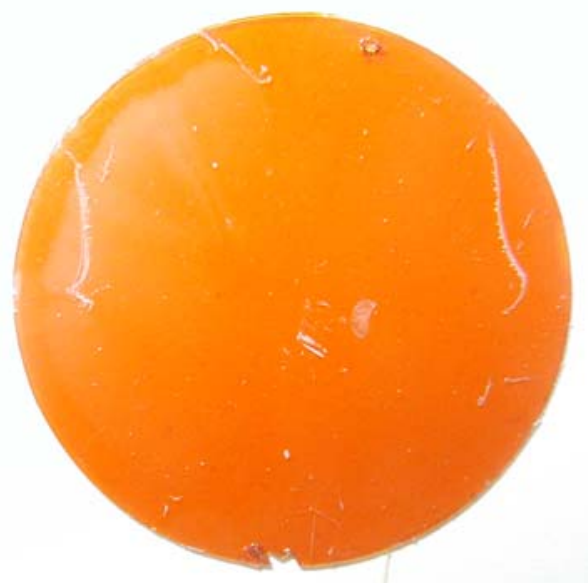

$2.54 \mathrm{~cm}$ diameter Kapton substrate

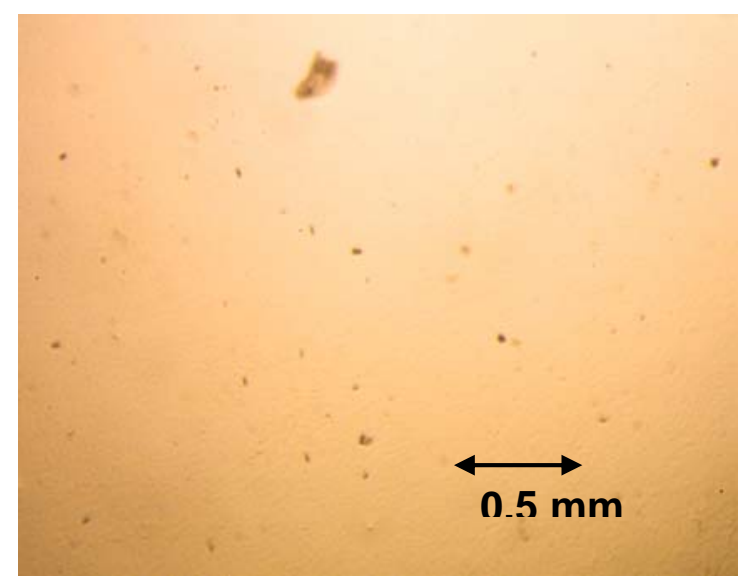

Fused silica substrate

a. Ceramer coated samples at a Kapton effective fluence of $2.22 \times 10^{21}$ atoms $/ \mathrm{cm}^{2}$.
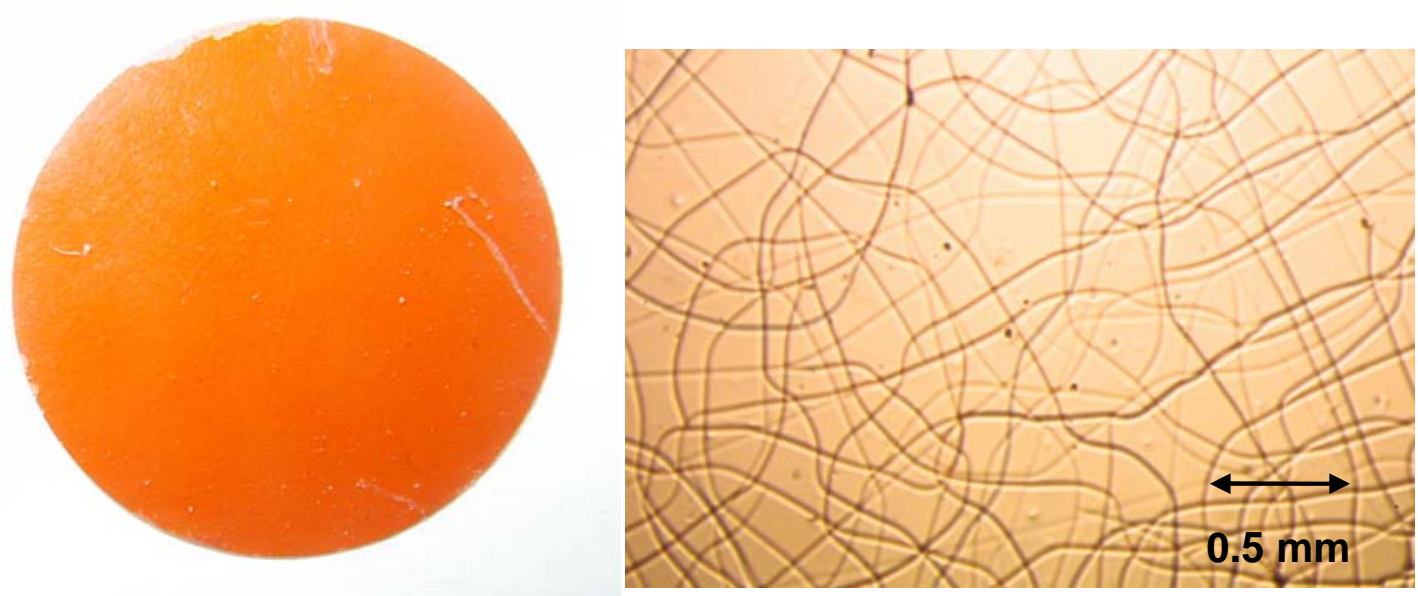

$2.54 \mathrm{~cm}$ diameter Kapton substrate

Fused silica substrate

b. DC93-500 coated samples at a Kapton effective fluence of $2.22 \times 10^{21}$ atoms $/ \mathrm{cm}^{2}$.

Figure 7. - Photographs of silicone coated Kapton $\mathrm{H}$ and silicone coated fused silica after atomic oxygen exposure to moderate and high fluence levels. 


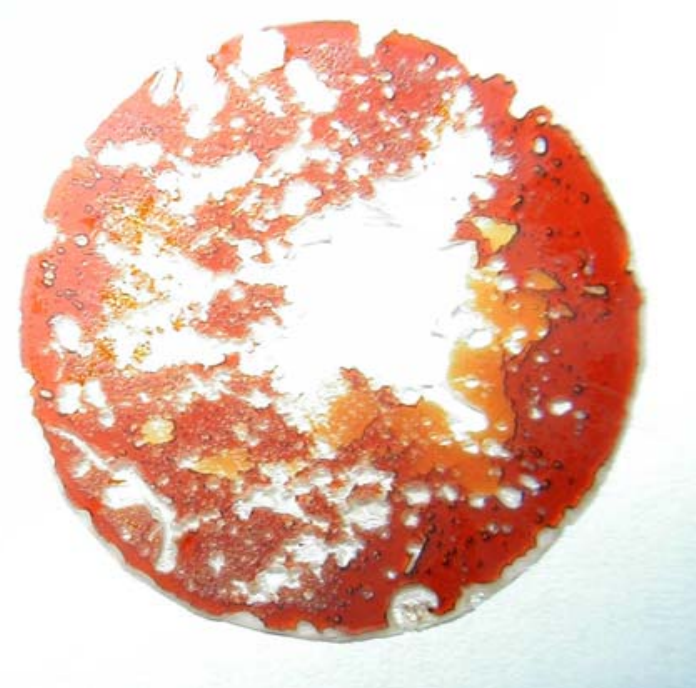

$2.54 \mathrm{~cm}$ diameter Kapton substrate

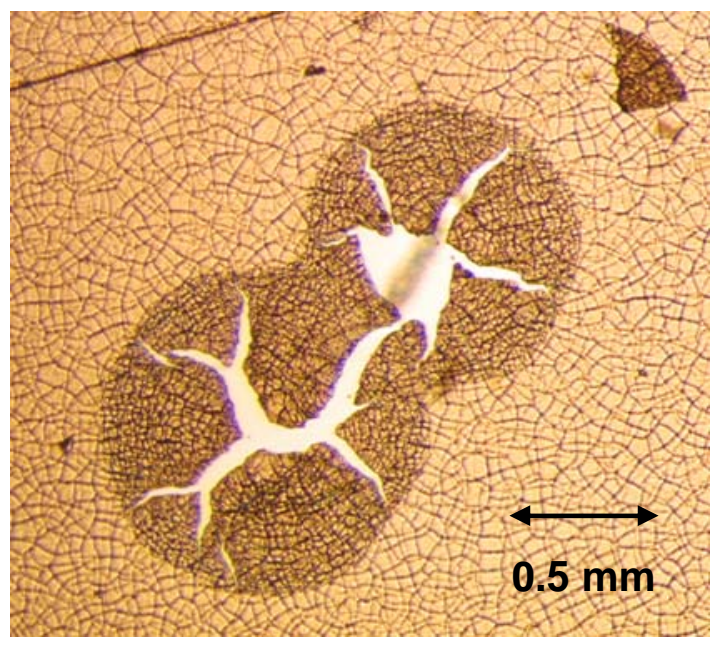

Fused silica substrate

c. Ceramer coated samples at a Kapton effective fluence of $1.38 \times 10^{22}$ atoms $/ \mathrm{cm}^{2}$.

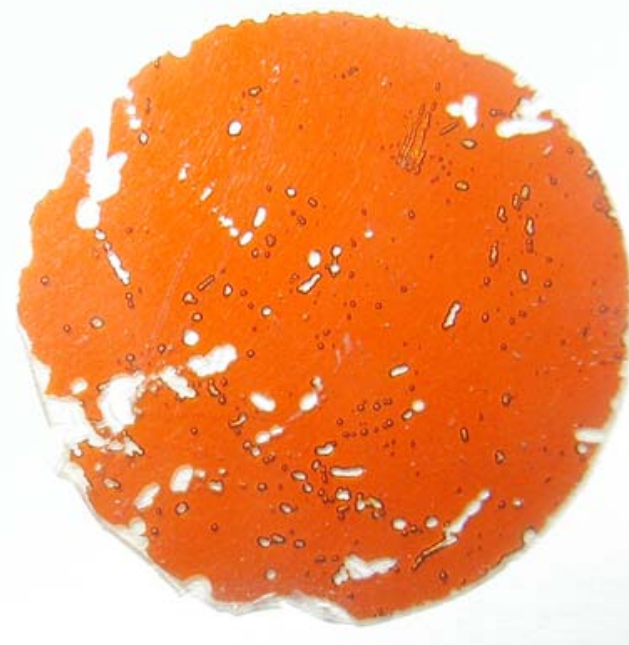

$2.54 \mathrm{~cm}$ diameter Kapton substrate

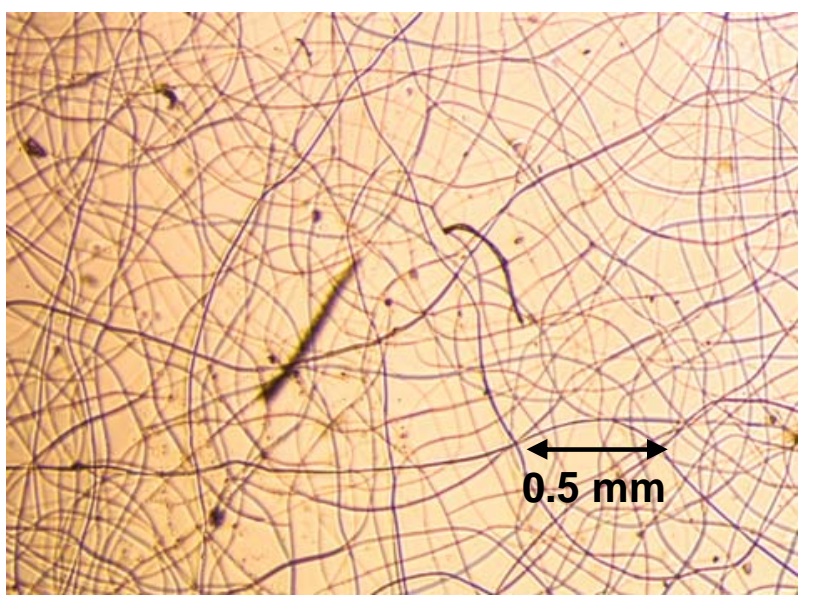

Fused silica substrate

d. DC93-500 coated samples at a Kapton effective fluence of $1.38 \times 10^{22}$ atoms $/ \mathrm{cm}^{2}$.

Figure 7. - (Concluded). Photographs of silicone coated Kapton $\mathrm{H}$ and silicone coated fused silica after atomic oxygen exposure to moderate and high fluence levels.

As can be seen in Figure 7, atomic oxygen exposure of the ceramer and DC93-500 provide excellent protection for moderate $\left(2.22 \times 10^{21}\right.$ atoms $\left./ \mathrm{cm}^{2}\right)$ fluence levels. The ceramer coating appears to be a significant improvement at moderate fluence levels in that there is no sign of microcracking as occurs for DC93-500. However, at high fluences $\left(1.38 \times 10^{22}\right.$ atoms $\left./ \mathrm{cm}^{2}\right)$ both the ceramer and DC93-500 develop microcracks. Unlike the 
DC93-500, the ceramer tends to detach from its substrate causing greater coating shrinkage due to atomic oxygen attack on both surfaces of the coating. This causes greater shrinkage and opening of the cracks thus allowing atomic oxygen to attack underlying Kapton. Thus, the ceramer coating is better for moderate fluences and could potentially be used for coating optical polymers such as Fresnel lenses for concentrators over solar cells. In such applications protective coatings that form microcracks would not be suitable due to loss in specular transmittance.

The mass loss of coated Kapton as a function of atomic oxygen fluence for both the ceramer and DC93-500 coatings is shown in Figure 8.

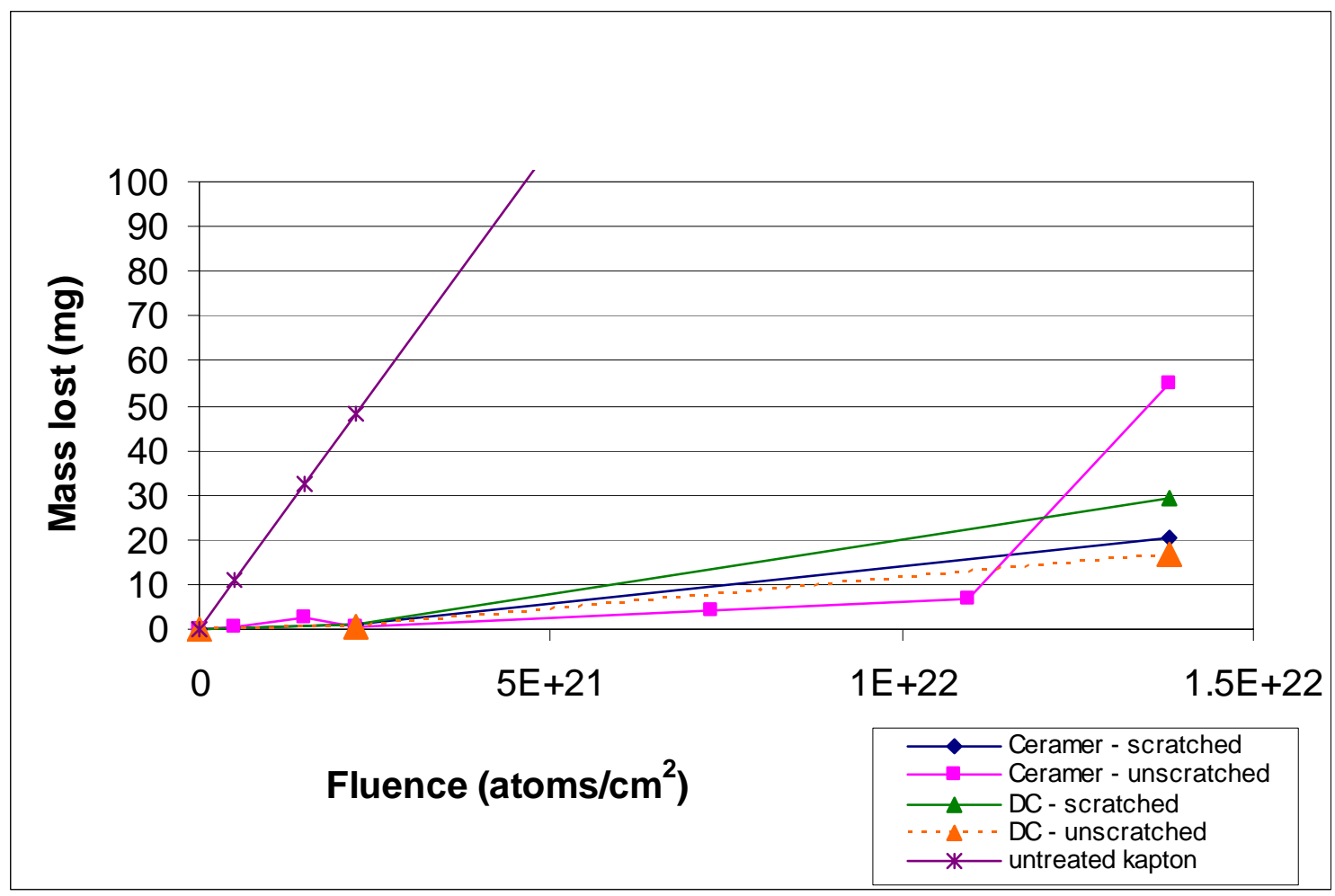

Figure 8. - Mass loss of coated Kapton as a function of atomic oxygen fluence for both the ceramer and DC93-500 coatings.

As can be seen from Figure 8, the ceramer coating as well as the DC93-500 coating does provide significant atomic oxygen protection for most fluences. However, at fluences above $1 \times 10^{22}$ atoms $/ \mathrm{cm}^{2}$, the ceramer coating develops apertures in it due to microcracking and the rate of oxidation of the underlying Kapton greatly increases. There did not seem to be significant differences in atomic oxygen protection resulting from the laboratory dust abrasion of the coatings. This is thought to be due to the very shallow scratches resulting without any going all the way through the coatings. 
Atomic oxygen exposure of the ceramer coatings cause an increase in absorptance and therefore reduction in transmittance for wavelengths $<800 \mathrm{~nm}$ with little change in reflectance as shown in Figure 9.

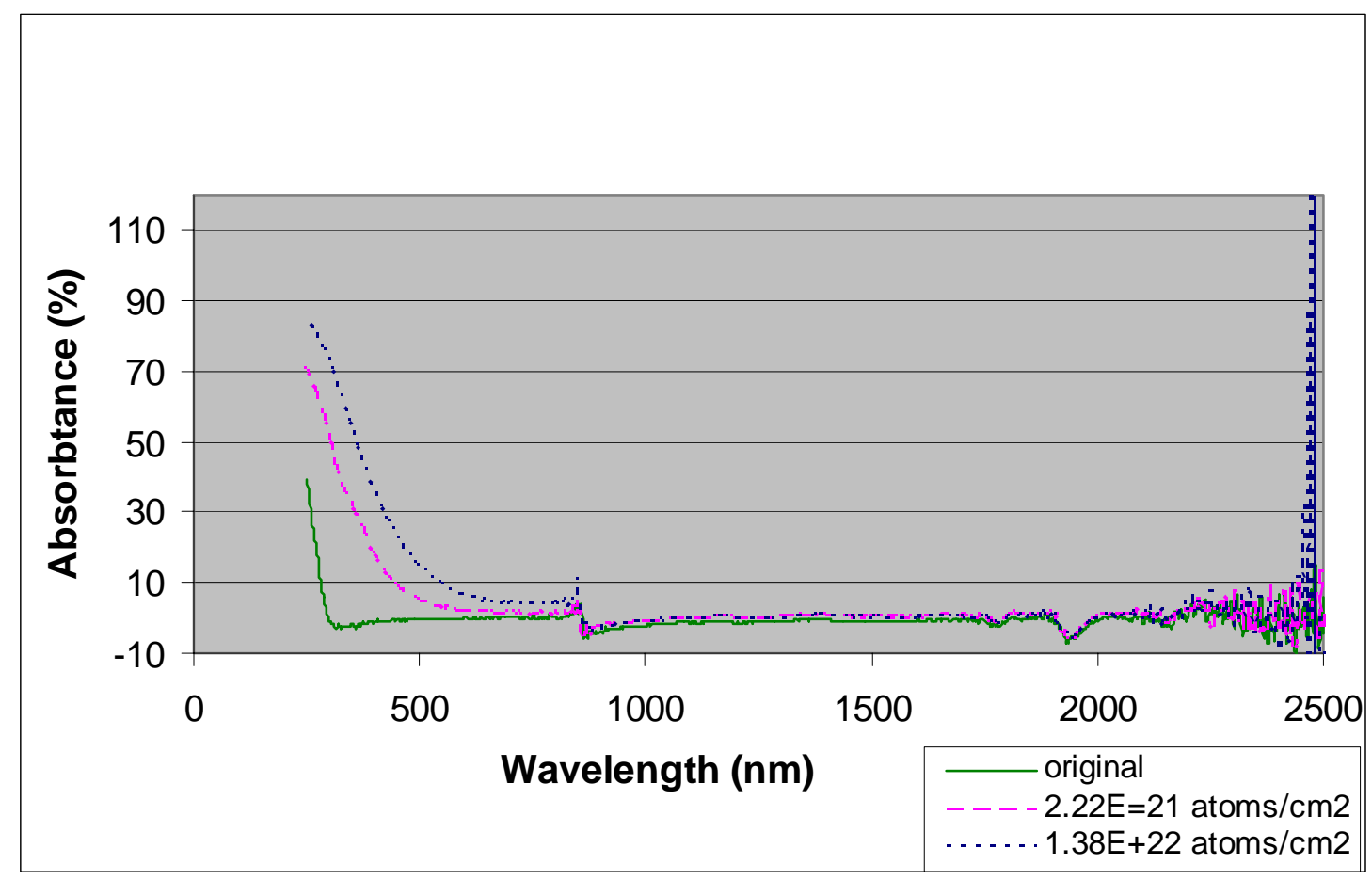

a. Total absorptance.

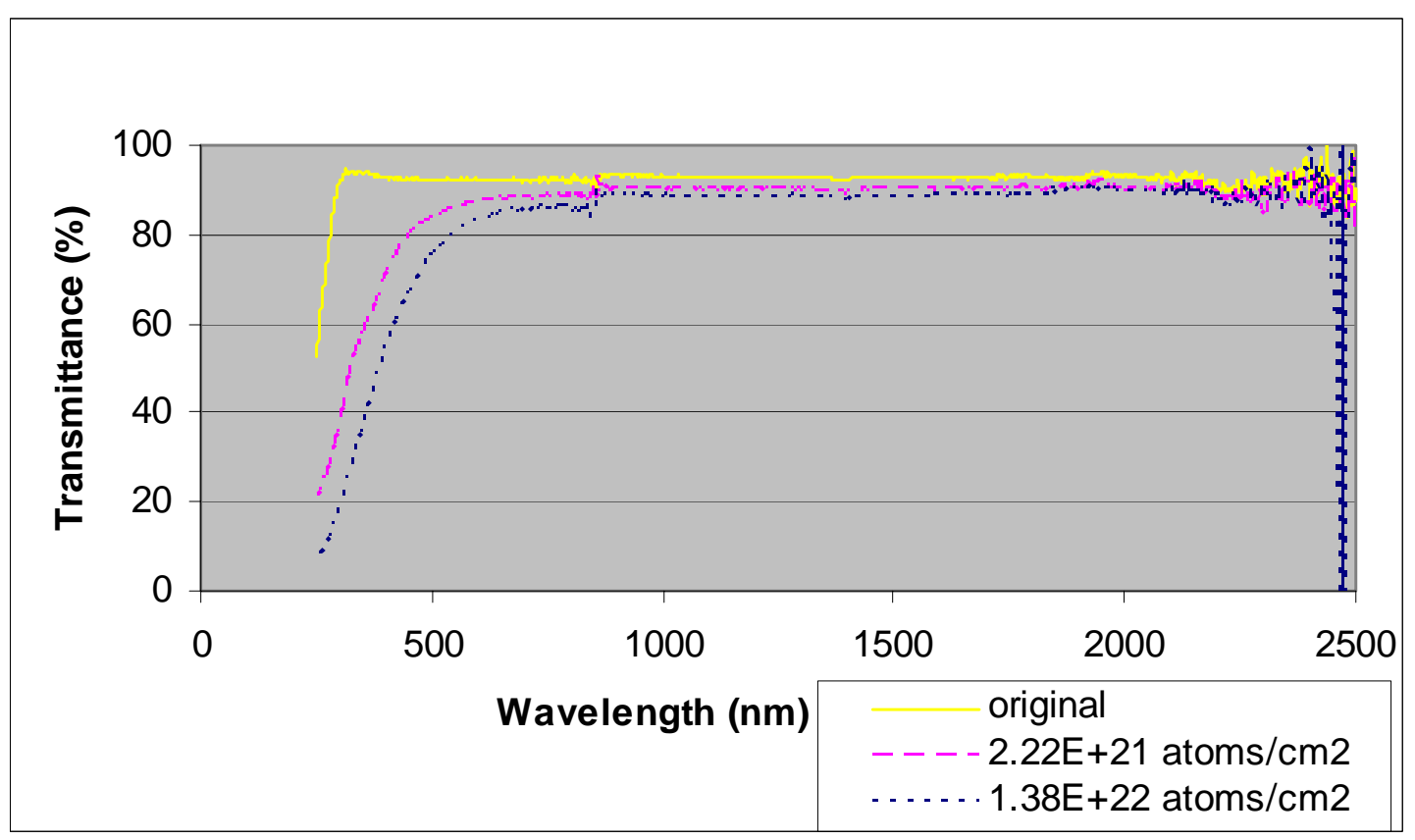

b. Total transmittance.

Figure 9. - Effects of atomic oxygen on total optical properties for creamer coated fused silica. 


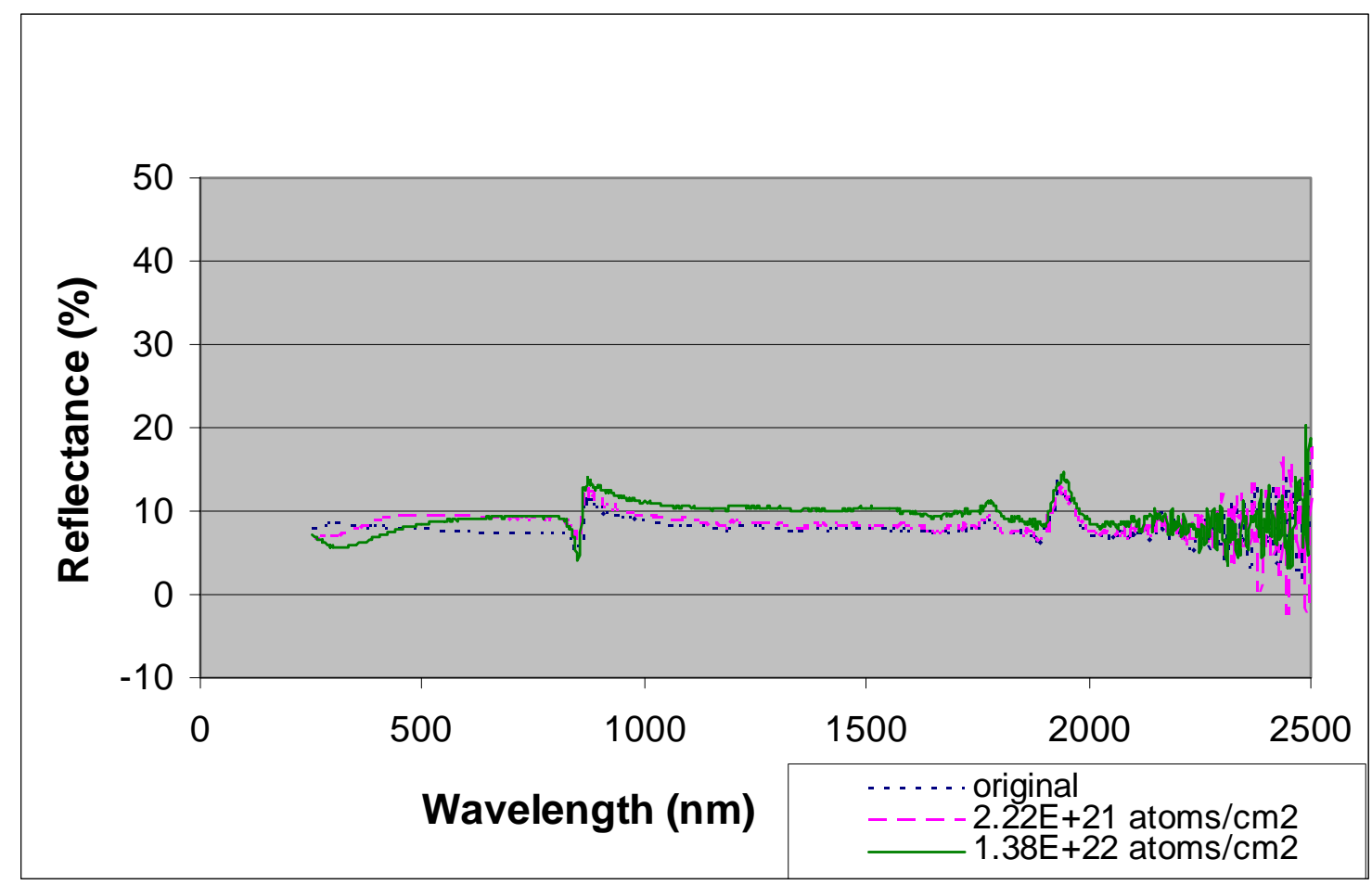

c. Total reflectance.

Figure 9. - (Concluded). Effects of atomic oxygen on total optical properties for creamer coated fused silica.

Similar results were observed for DC93-500 and the ceramer as shown in Figure 10. However, if one considers applications such as protective coatings for Fresnel concentrator solar cell arrays there is an important distinction between the two coatings for moderate fluences. The specular transmittance degradation caused by atomic oxygen exposure is in part due to increased absorption for wavelengths $<800 \mathrm{~nm}$ as well as microcracking as shown in Figure 11. 


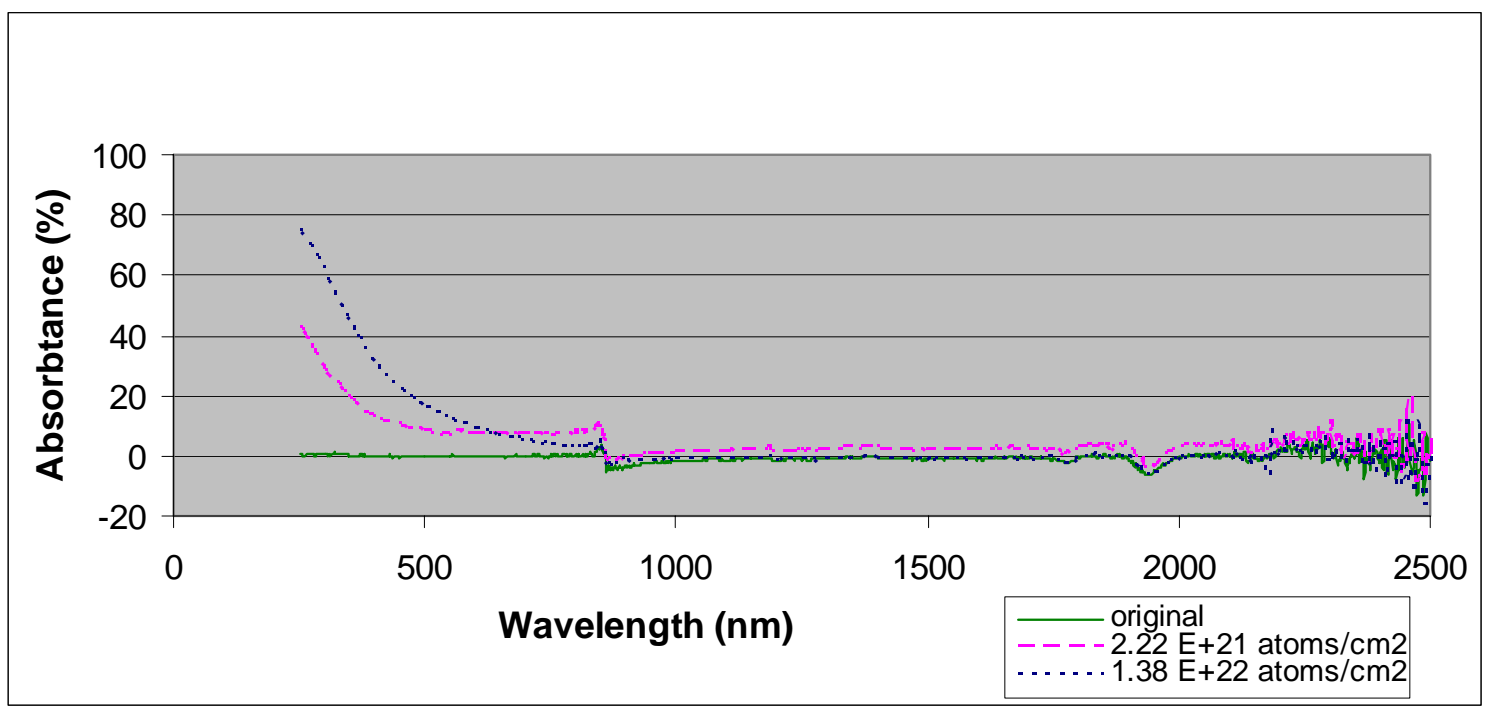

a. Total absorptance.

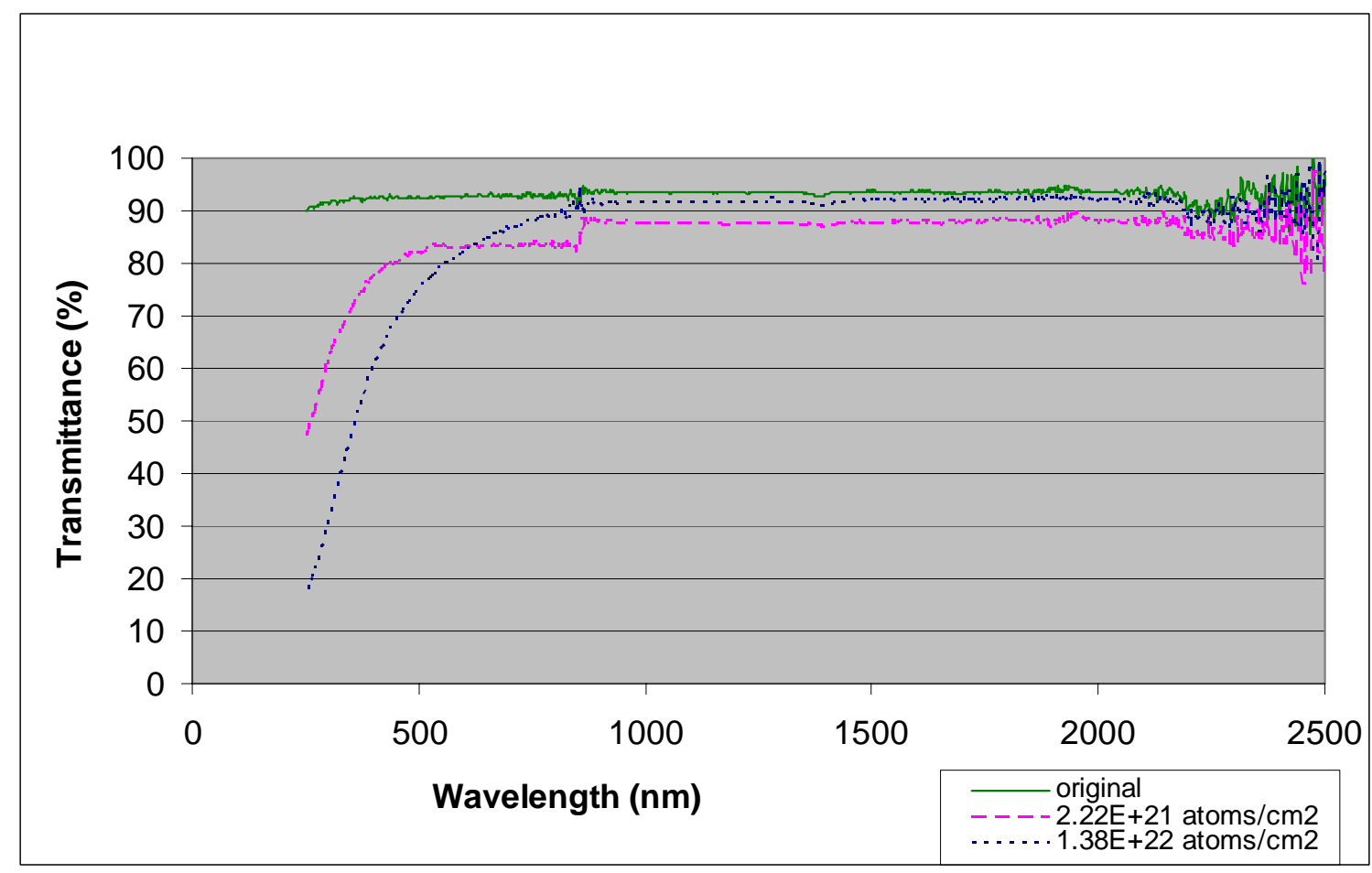

b. Total transmittance.

Figure 10. - Effects of atomic oxygen on total optical properties for DC93-500 coated fused silica. 


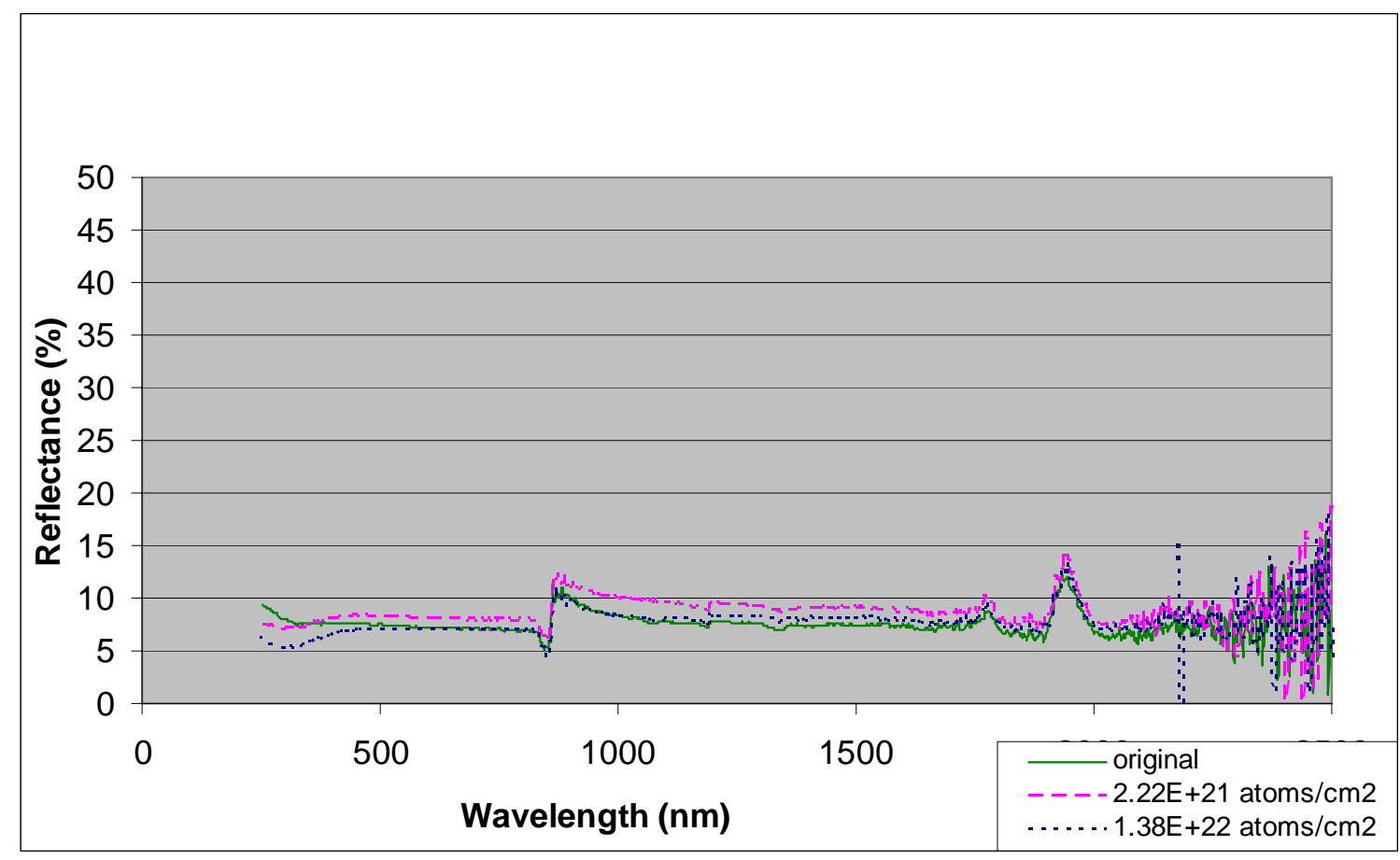

c. Total reflectance.

Figure 10. - (Concluded). Effects of atomic oxygen on total optical properties for DC93500 coated fused silica.

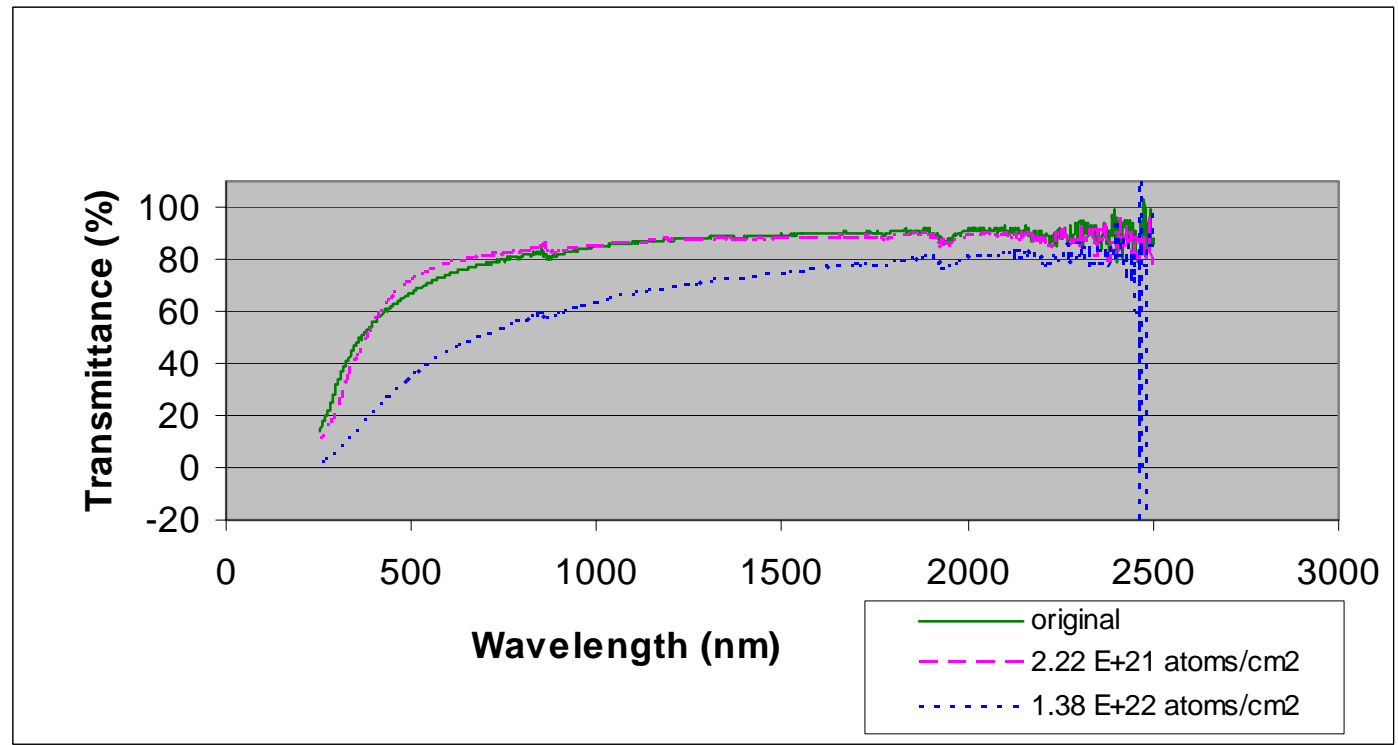

a. Ceramer.

Figure 11. - Effects of atomic oxygen on specular transmittance of ceramer and DC93500 coated fused silica. 


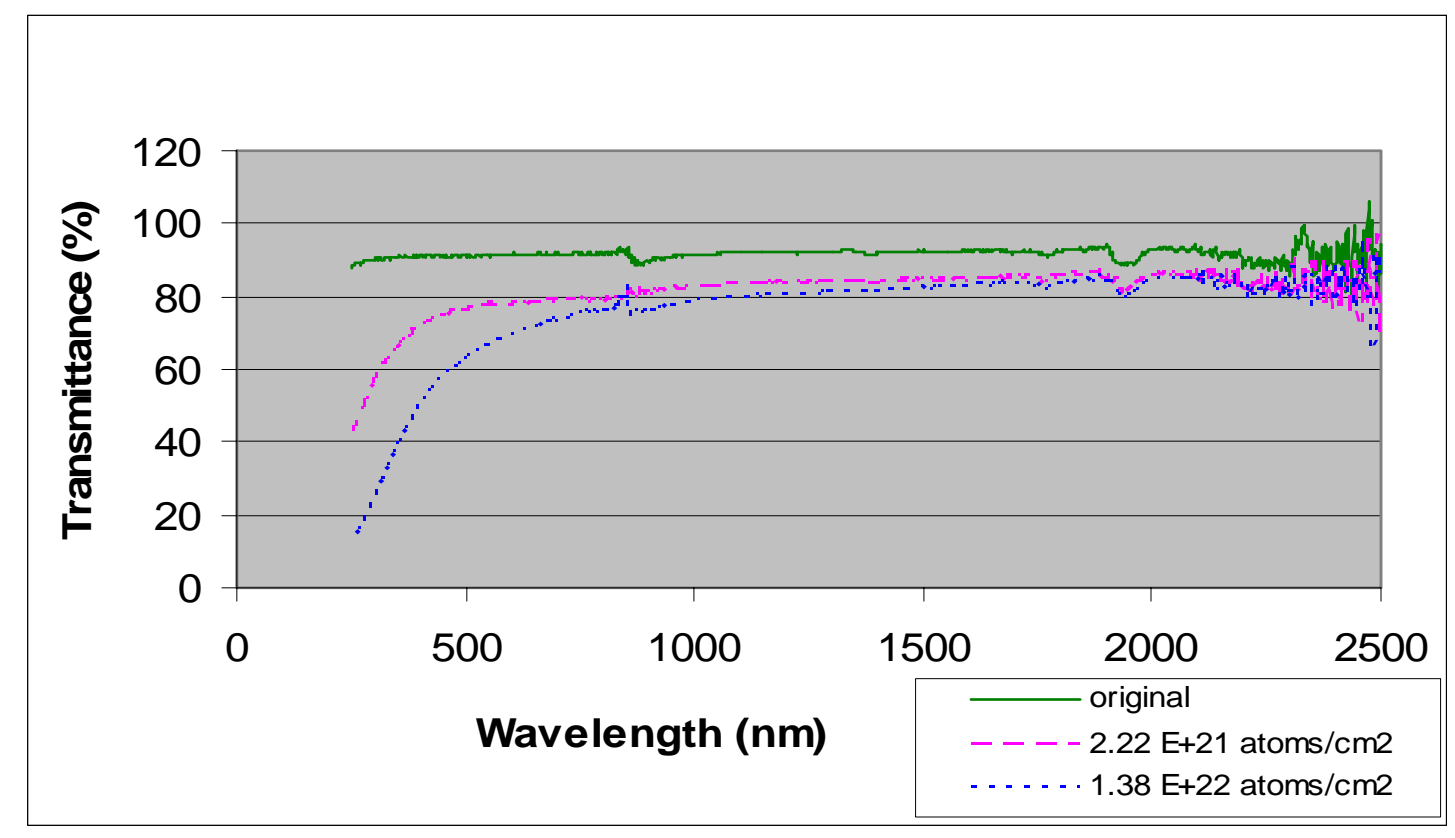

b. DC93-500

Figure 11. - (Concluded). Effects of atomic oxygen on specular transmittance of ceramer and DC93-500 coated fused silica.

As can be seen by examining Figures 11 (a) and 7 ( $a$ and b), the absence or presence of microcracking at a fluence level of $2.22 \times 10^{21}$ atoms $/ \mathrm{cm}^{2}$ makes a significant impact on specularly transmitted light. The ceramer coating does allow much greater specular transmittance than the DC93-500 for fluences up to $2.22 \times 10^{21}$ atoms $/ \mathrm{cm}^{2}$.

X-ray photoelectron spectroscopy was performed in order to confirm the presence of a protective oxide layer (Figure 12). It is important to note that sputtering was not performed during the analysis. This ensures that only the surface of the samples was analyzed. The initial XPS spectrum shows high amounts of both silicon and oxygen, which is expected since these elements are present in the polymer backbone. After atomic oxygen exposure the oxygen peak increased while the silicon peaks decreased. This is anticipated due to the protective oxide layer possessing a high amount of oxygen compared to silicon. The oxide layer should be composed of silicon atoms whose valences are filled by oxygen atoms, yielding a Si- $\mathrm{O}_{4}$ network. The presence of carbon after exposure to atomic oxygen is due to impurities on the surface of the film such as dust, dirt, etc. and is, therefore, always present (Ref. 12). 


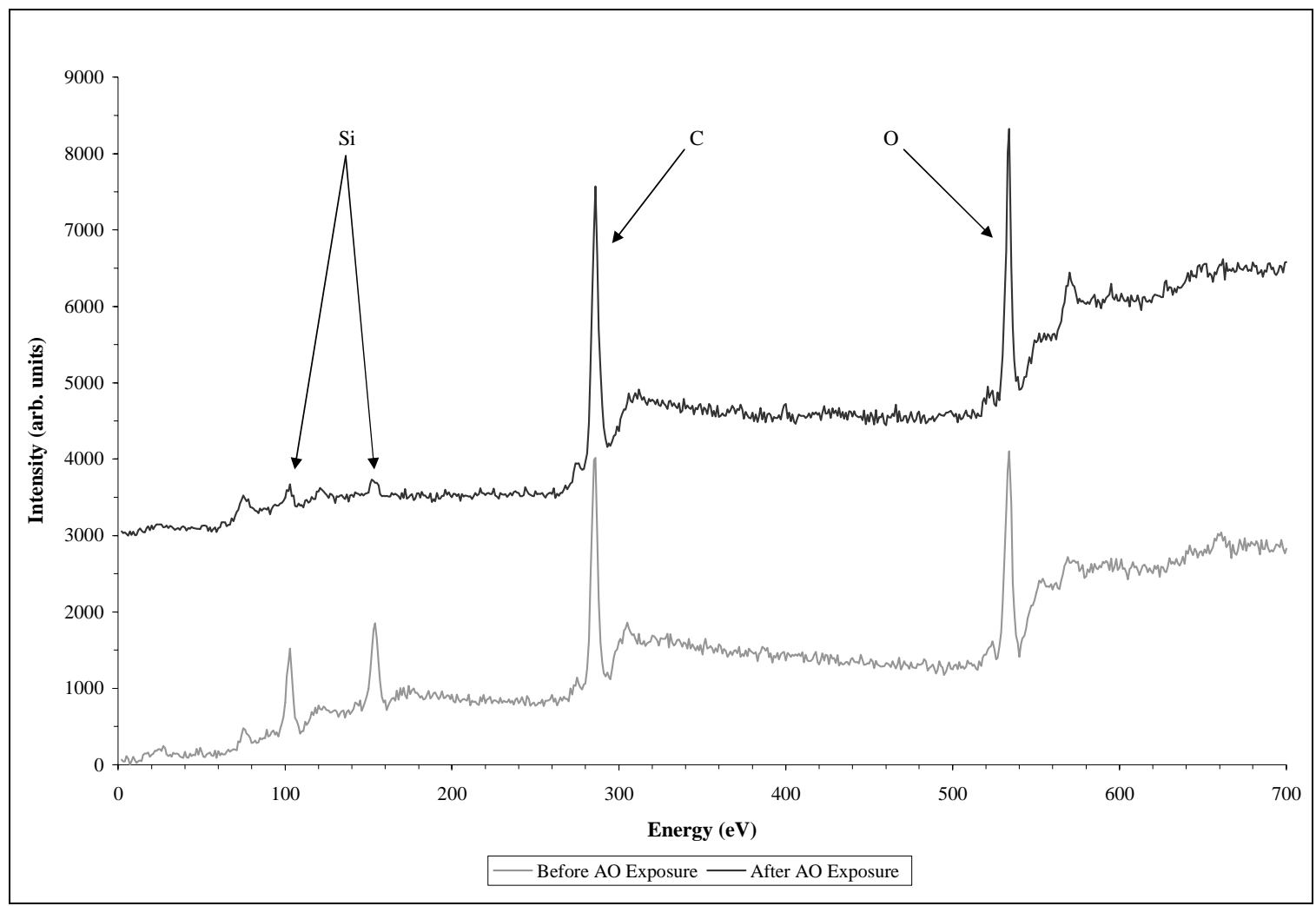

Figure 12. - XPS Spectrum of the Cross-linked Methyl Substituted Polysiloxane Before and After Atomic Oxygen Exposure

Cross contamination tests performed separately on the ceramer and DC93-500 coating using fused silica witness slides adjoining the silicone samples indicated that there was transport of short chain silicones to the fused silica that resulted in a silica deposit 857 Angstroms for a Kapton effective fluence of $1 \times 10^{22}$ atoms $/ \mathrm{cm}^{2}$ for the ceramer, but no measurable contamination from the DC93-500. This is probably due to the lack of vacuum stripping of the ceramer whereas the DC93-500 is vacuum stripped. A "no sample" test of the facility did, in fact, result in no deposit of oxidized silicone.

\subsection{CONCLUSIONS}

Atomic oxygen exposure of ceramer and DC93-500 silicone coated Kapton $\mathrm{H}$ and fused silica slides indicates the ceramer coating has superiority over DC93-500 coatings for moderate (up to $2.22 \times 10^{21}$ atoms $/ \mathrm{cm}^{2}$ ) Kapton effective atomic oxygen fluences. The ceramer coatings at this fluence resulted in low mass loss of coated Kapton samples and did not show evidence of the extended microcracking that occurred for DC93-500. This results in superior specular light transmittance for the ceramer coatings. This may allow its use as atomic oxygen protective coatings over silicone Fresnel concentrators for solar arrays. At high fluence levels $\left(1.38 \times 10^{22}\right.$ atoms $\left./ \mathrm{cm}^{2}\right)$ the ceramer coating develops microcracks that result in detachment of the coating causing exposure of the underlying Kapton which does not occur for DC93-500. Thus at high fluences DC93-500 would be a better choice of protective coating. 
The ceramer coating produced cross contamination of silica on witness slides which suggests that the ceramer should be vacuum stripped to prevent the transport of short chain silicones that can result in contamination.

\subsection{REFERENCES}

1. Banks, B.A., Dever, J.A., Gebauer, L., and Hill, C.M., "Atomic Oxygen Interactions with FEP Teflon and Silicones on LDEF," presented at the 1st LDEF Post-Retrieval Symposium, Kissimmee, Florida, June 2-8, 1991.

2. Banks, B.A., Rutledge, S.K., de Groh, K.K., Mirtich, M.J., Gebauer, L., Olle, R., and Hill, C.M., "The Implications of the LDEF Results on Space Station Freedom Power System Materials," presented at the 5th International Symposium on Materials in a Space Environment, Cannes-Mandelieu, France, September 16-20, 1991.

3. Banks, B., Rutledge, S., Sechkar, E., Stueber, T., Snyder, A., Hatas, C., and Brinker, D., "Issues and Effects of Atomic Oxygen Interactions With Silicone Contamination on Spacecraft in Low Earth Orbit," NASA/TM-2000-210056, proceedings of the $8^{\text {th }}$ International Symposium on Materials in a Space Environment and the $5^{\text {th }}$ International Conference on Protection of Materials and Structures from the LEO Space Environment cosponsored by the CNES, Integrity Testing Laboratory, ESA, ONERA and the Canadian Space Agency, Arcachon, France, June 4-9, 2000.

4. de Groh, K., Banks, B., Ma, D., "Ground-Laboratory To In-Space Effective Atomic Oxygen Fluence Determination for DC 93-500 Silicone," $7^{\text {th }}$ International Conference on ""Protection of Materials and Structures form Space Environment," Toronto, Canada, May 10-13, 2004.

5. Rutledge, S., Cooper, J. and Olle, R., "The Effect of Atomic Oxygen on PolysiloxanePolyimide for Spacecraft Applications in Low Earth Orbit," Proceedings of the Space Operations Applications and Research Symposium, NASA CP-3103, Albuquerque, NM, June 26-28, 1990.

6. Hung, C, "Reaction and Protection of Wire Insulators in Atomic Oxygen Environment," NASA TM 106767, 1994.

7. Zhang, C., Babonneau, F., Bonhomme, C., Laine, R.M. Soles, C.L., Hristov, H.A., Yee, A.F., "Highly Porous Polyhedral Silsesquioxane Polymers. Synthesis and Characterization,” J. Am. Chem. Soc. 120, 8380-8391. 1998.

8. Brunsvold, A.L., Minton, T.K., Gouzman, I., Grossman, E. and Gonzalez, R.I. “An investigation of the Resistance of POSS Polyimide to Atomic Oxygen Attack," submitted to Journal of High Performance Polymers, 2003.

9. Soucek, M.D. and Tuman, S.J., J. Coat. Technol., 68 (854), 73 (1996). 
10. Tuman, S.J., Chamberlain, D., Scholsky, K.M., and Soucek, M.D., Prog. Org. Coat., 28, 251 (1996).

11. Wold, C.R. and Soucek, M.D., J. Coat. Tech., 70, 43 (1997).

12. Dworak, D.P. and Soucek, M.D., Prog. Org. Coat., 47, 448 (2003).

13. ASTM E 2089-00, "Standard Practices for Ground Laboratory Atomic Oxygen Interaction Evaluation of Materials for Space Applications," June 2000.

14. Smith, A.L. “The Analytical Chemistry of Silicones', Wiley, New York, (1991).

15. Kang, D.W., Rajendran, G.P., and Zeldin, M., J. Polym. Sci. Part A. Polym. Chem., 24, 1085 (1986).

16. N. Grassie and I.G. Macfarlane, Eur. Polym. J., 14, 875 (1978). 
Public reporting burden for this collection of information is estimated to average 1 hour per response, including the time for reviewing instructions, searching existing data sources, gathering and maintaining the data needed, and completing and reviewing the collection of information. Send comments regarding this burden estimate or any other aspect of this collection of information, including suggestions for reducing this burden, to Washington Headquarters Services, Directorate for Information Operations and Reports, 1215 Jefferson Davis Highway, Suite 1204, Arlington, VA 22202-4302, and to the Office of Management and Budget, Paperwork Reduction Project (0704-0188), Washington, DC 20503.

1. AGENCY USE ONLY (Leave blank) 2. REPORT DATE 3. REPORT TYPE AND DATES COVERED

\section{TITLE AND SUBTITLE}

April 2004

Technical Memorandum

Atomic Oxygen Durability Evaluation of a UV Curable Ceramer

Protective Coating

6. AUTHOR(S)

Bruce A. Banks, Christina A. Karniotis, David Dworak, and Mark Soucek

\section{PERFORMING ORGANIZATION NAME(S) AND ADDRESS(ES)}

National Aeronautics and Space Administration

John H. Glenn Research Center at Lewis Field

Cleveland, Ohio 44135-3191
WBS-22-319-20-E1

\section{FUNDING NUMBERS}

8. PERFORMING ORGANIZATION REPORT NUMBER

E-14573

\section{SPONSORING/MONITORING AGENCY NAME(S) AND ADDRESS(ES)}

10. SPONSORING/MONITORING AGENCY REPORT NUMBER

NASA TM-2004-213098

\section{SUPPLEMENTARY NOTES}

Prepared for the Seventh International Conference on Protection of Materials and Structures from Space Environment cosponsored by Materials Manufacturing Ontario; and The Centre for Research in Earth and Space Technology (CRESTech), Toronto, Canada, May 10-13, 2004. Bruce A. Banks, NASA Glenn Research Center; Christina A. Karniotis, QSS Group, Inc., 21000 Brookpark Road, Cleveland, Ohio 44135; and David Dworak and Mark Soucek, University of Akron, 302 Buchtel Mall, Akron, Ohio 44325. Responsible person, Bruce A. Banks, organization code 5480, 216-433-2308.

12a. DISTRIBUTION/AVAILABILITY STATEMENT 12b. DISTRIBUTION CODE

Unclassified - Unlimited

Subject Category: 75

Distribution: Nonstandard

Available electronically at http://gltrs.grc.nasa.gov

This publication is available from the NASA Center for AeroSpace Information, 301-621-0390.

\section{ABSTRACT (Maximum 200 words)}

The exposure of most silicones to atomic oxygen in low Earth orbit (LEO) results in the oxidative loss of methyl groups with a gradual conversion to oxides of silicon. Typically there is surface shrinkage of oxidized silicone protective coatings which leads to cracking of the partially oxidized brittle surface. Such cracks widen and branch crack with continued atomic oxygen exposure ultimately allowing atomic oxygen to reach any hydrocarbon polymers under the silicone coating. A need exists for a paintable silicone coating that is free from such surface cracking and can be effectively used for protection of polymers and composites in LEO. A new type of silicone based protective coating holding such potential was evaluated for atomic oxygen durability in an RF atomic oxygen plasma exposure facility. The coating consisted of a UV curable inorganic/organic hybrid coating, known as a ceramer, which was fabricated using a methyl substituted polysiloxane binder and nanophase silicon-oxo-clusters derived from sol-gel precursors. The polysiloxane was functionalized with a cycloaliphatic epoxide in order to be cured at ambient temperature via a cationic UV induced curing mechanism. Alkoxy silane groups were also grafted onto the polysiloxane chain, through hydrosilation, in order to form a network with the incorporated silicon-oxo-clusters. The prepared polymer was characterized by ${ }^{1} \mathrm{H}$ and ${ }^{29} \mathrm{Si} \mathrm{NMR}$, FT-IR, and electrospray ionization mass spectroscopy. The paper will present the results of atomic oxygen protection ability of thin ceramer coatings on Kapton $\mathrm{H}$ as evaluated over a range of atomic oxygen fluence levels.

14. SUBJECT TERMS

Atomic oxygen; Silicones 15. NUMBER OF PAGES 26

\begin{tabular}{|c|c|c|}
\hline $\begin{array}{c}\text { 17. SECURITY CLASSIFICATION } \\
\text { OF REPORT } \\
\text { Unclassified }\end{array}$ & $\begin{array}{c}\text { 18. SECURITY CLASSIFICATION } \\
\text { OF THIS PAGE } \\
\text { Unclassified }\end{array}$ & $\begin{array}{c}\text { 19. SECURITY CLASSIFICATION } \\
\text { OF ABSTRACT } \\
\text { Unclassified }\end{array}$ \\
\hline
\end{tabular}



